\title{
Ara-C increases gastric cancer cell invasion by upregulating CD-147-MMP-2/MMP-9 via the ERK signaling pathway
}

\author{
GUANG-LIN YANG $^{1 *}$, HAI-RONG TAO ${ }^{2 *}$, HAN-WEI WANG $^{4}$, YUN SUN $^{5}$, LI-DI ZHANG $^{6}$, \\ CHAO ZHANG $^{6}$, WEI HE ${ }^{6}$, MANG-HUA XU ${ }^{6}$, JIANG-MIN ZHAO ${ }^{3}$ and FENG-HOU GAO ${ }^{6}$ \\ Departments of ${ }^{1}$ General Surgery, ${ }^{2}$ Orthopaedic Surgery and ${ }^{3}$ Radiology, Shanghai 9 th People's Hospital, Shanghai Jiao \\ Tong University School of Medicine, Shanghai 200011; ${ }^{4}$ Department of Hematology and Rheumatology, \\ Bengbu Third People's Hospital Affiliated to Southeast University, Bengbu, Anhui 233000; ${ }^{5}$ Department of Clinical \\ Laboratory, Dong-Nan Hospital, Shanghai 200023; ${ }^{6}$ Institute of Oncology, Shanghai 9th People's Hospital, \\ Shanghai Jiao Tong University School of Medicine, Shanghai 200011, P.R. China
}

Received September 10, 2014; Accepted December 2, 2014

DOI: $10.3892 / o r .2015 .3748$

\begin{abstract}
Gastric cancer cell are not particularly sensitive to Ara-C, a deoxycytidine analog that affects DNA synthesis. In the present study, AGS and MKN-45 gastric cancer cell lines were treated with Ara-C to determine its role in cell proliferation and apoptosis. The antiproliferative effect of Ara- $\mathrm{C}$ was assessed using the Cell Counting kit-8. Gelatinase zymography was utilized to detect the activity of MMP-2 and MMP-9, and an in vitro invasion assay was performed. Using RT-PCR, CD-147, MMP-2 and MPP-9 mRNA levels were assessed in AGS cells with various doses of Ara-C treatment. CD-147, MMP-2 and MMP-9 protein levels were analysed in Ara-C-treated AGS and MKN-45 cells. AGS cells were treated with or without U-0126 or siRNA-CD147 and/or Ara-C for $24 \mathrm{~h}$, and an in vitro invasion assay was performed. Although low-dose Ara-C had no obvious effect on cell proliferation, it upregulated the expression of MMP-2, MMP-9 and CD-147 and ERK activation. Low-dose Ara-C increased gastric cancer cell invasion. U-0126 and siRNA-CD-147 inhibited the induction of Ara-C in gastric cancer cell invasion. Therefore, Ara-C
\end{abstract}

Correspondence to: Professor Feng-Hou Gao, Institute of Oncology, Shanghai 9th People's Hospital, Shanghai Jiao Tong University School of Medicine, 639 Zhi Zao Ju Road, Shanghai 200011, P.R. China

E-mail: fenghougao@163.com

Professor Jiang-Min Zhao, Department of Radiology, Shanghai 9th People's Hospital, Shanghai Jiao Tong University School of Medicine, 639 Zhi Zao Ju Road, Shanghai 200011, P.R. China

E-mail: johnmzhao@sjtu.edu.cn

*Contributed equally

Key words: Ara-C, gastric cancer cell, MMP-2, MMP-9, CD-147, proliferation, invasion enhances the invasiveness of gastric cancer cells by expression of CD-147 /MMP-2 and MMP-9 via the ERK signaling pathway. The results are therefore useful in the prevention of Ara-C collateral damage associated with standard, conventional protocols of chemotherapy administration.

\section{Introduction}

Radical treatment of gastric cancer is possible if the disease is diagnosed at an early stage, prior to metastasis. Gastric cancer causes approximately 800,000 deaths worldwide annually (1). Prognosis is poor and the 5-year survival rate is $<5-15 \%$, as most patients present with advanced disease. Advanced gastric cancer is not particularly sensitive to chemotherapy (2) as the benefits of these different drugs, independently or in combination remain to be elucidated. Resistance of tumor cells towards chemotherapeutic drugs and tumor metastasis have been observed. Of patients presenting with metastatic cancer $\sim 90 \%$ become resistant to chemotherapy (3). This occurs readily in cancers of the breast, prostate, lung, pancreas and colon (4-8). Therefore, it is necessary to re-evaluate the drugs commonly used in the treatment of gastric cancer.

Ara-C, a deoxycytidine analog affecting DNA synthesis, is an effective inhibitor that changes into diphosphate or triphosphare cytarabine via phosphatase in vivo. Triphosphare cytarabine can be a powerful inhibitor of the synthesis of DNA polymerase, which can inhibit the conversion of cytidine diphosphate into deoxycytidine diphosphate, thus inhibiting polymerization and synthetic DNA and interfering with cell proliferation (9). Due to its inhibitory effect on cell proliferation, Ara- $\mathrm{C}$ as a routine anticancer drug is widely and effectively used in the clinical treatment of leukemia (10). The treatment of gastric cancer with Ara-C as well as the underlying mechanism involved remain to be elucidated.

In the present study, we found that Ara-C did not inhibit gastric cancer cell proliferation. Conversely, Ara-C was able to activate the ERK signaling pathway, resulting in the high expression of CD-147-MMP-2/MMP-9 and an increase in the aggressiveness of gastric cancer cells. 


\section{Materials and methods}

Reagents. Ara-C was obtained from Sigma (St. Louis, MO, USA). It was dissolved in sterile $\mathrm{H}_{2} \mathrm{O}$ to a stock concentration of $0.4 \mathrm{~g} / \mathrm{ml}$. U-0126 was obtained from Cell Signaling Technology (Beverly, MA, USA) and dissolved in DMSO (Sigma) at a stock concentration of $10 \mathrm{mM}$. The stock solutions were wrapped in foil and maintained at $4^{\circ} \mathrm{C}$ or $-20^{\circ} \mathrm{C}$.

Cell cultures. NB4 and Jurkat cell lines and the AGS and MKN-45 gastric cancer cell line were purchased from the Shanghai Institutes for Biological Sciences (Shanghai, China). The cells were maintained in humidified room air containing $5 \% \mathrm{CO}_{2}$ at $37^{\circ} \mathrm{C}$, NB4 and Jurkat were cultured in RPMI-1640 medium and AGS and MKN-45 cells were cultured in DMEM medium supplemented with $10 \%$ fetal bovine serum (FBS) and $1 \%$ penicillin-streptomycin. RPMI-1640, DMEM and FBS were purchased from Gibco-BRL (Gibco, Long Island, NY, USA). Cells in the logarithmic phase of growth were used in all the experiments.

Cell Counting Kit-8. The cells were seeded at a concentration of $2 \times 10^{3}$ cells $/ 200 \mu 1 /$ well in 96 -well culture plates for a cell proliferation assay with Cell Counting Kit-8 reagent (CCK-8; Dojindo Molecular Technologies, Inc., Kumamoto, Japan). Briefly, the cultured wells were treated with $20 \mu \mathrm{l} /$ well of CCK- 8 for $2 \mathrm{~h}$ prior to the end of incubation and the optical density of wells was measured at $450 \mathrm{~nm}$ using a microplate reader (Bio-Rad, Hercules, CA, USA). Results of the cell proliferation measurement were expressed as the absorbance at OD450.

Gelatinase zymography. Gelatinase zymography was performed in $10 \%$ Novex pre-cast SDS polyacrylamide gel in the presence of $0.1 \%$ gelatin under non-reducing conditions. Culture media $(20 \mu \mathrm{l})$ were mixed with sample buffer and loaded with SDS-PAGE with Tris glycine SDS buffer, according to the manufacturer's instructions (Novex). The samples were not boiled prior to electrophoresis. Following electrophoresis the gels were washed twice in $2.5 \%$ Triton X-100 for $30 \mathrm{~min}$ at room temperature to remove SDS. The gels were then incubated at $37^{\circ} \mathrm{C}$ overnight in substrate buffer containing $50 \mathrm{mM}$ Tris $\mathrm{HCl}$ and $10 \mathrm{mM} \mathrm{CaCl}_{2}$ at $\mathrm{pH} 8.0$, stained with $0.5 \%$ Coomassie blue R250 in 50\% methanol and 10\% glacial acetic acid for $30 \mathrm{~min}$, and destained. Protein standards were run concurrently and approximate molecular weights were determined by plotting the relative mobilities of known proteins.

RNA extraction and reverse transcriptase-polymerase chain reaction $(R T-P C R)$. Total RNA was extracted from the cells using RNAiso ${ }^{\mathrm{TM}}$ plus (Takara Bio, Otsu, Japan). The concentration and purity of RNA were determined by absorbance at $260 / 280 \mathrm{~nm}$. cDNA was synthesized from $1-\mu \mathrm{g}$ total RNA using an RNA PCR kit (both from Takara Bio, Shiga, Japan). Total RNA was reverse transcribed (10 $\mu 1$ of total volume) at $42^{\circ} \mathrm{C}$ for $30 \mathrm{~min}, 99^{\circ} \mathrm{C}$ for $5 \mathrm{~min}$ and $4^{\circ} \mathrm{C}$ for $5 \mathrm{~min}$. The total volume of PCR reaction was $20 \mu 1$. PCR conditions were 1 cycle at $94^{\circ} \mathrm{C}$ for $2 \mathrm{~min}, 30$ cycles at $94^{\circ} \mathrm{C}$ for $30 \mathrm{sec}, 55^{\circ} \mathrm{C}$ for $30 \mathrm{sec}$, and $72^{\circ} \mathrm{C}$ for $2 \mathrm{~min}$. The primers used were: GAPDH forward: 5'-TGG ACT CTG GAA TCC ATT CTG-3' and reverse: 5'-AAA ATC CCT GTT CCC ACT CA-3', CD-147 forward: 5'-CCA TGC TGG TCT GCA AGT CAG-3' and reverse: 5'-CCG TTC ATG AGG GCC TTG TC-3', MMP-2 forward: 5'-GAA GGC TGT GTT CTT TGC AG-3' and reverse: 5'-AGG CTG GTC AGT GGC TTG-3' and MMP-9 forward: 5'-TGC CAG TTT CCA TTC ATC TTC CAA-3' and reverse: 5'-CTG CGG TGT GGT GGT GGT T-3'. PCR was performed on Bio-Rad MyCycler and PCR products were separated by $1.5 \%$ agarose gel electrophoresis. Images were captured using a gel imaging system (Bio-Rad, Hercules, CA, USA).

Short-interfering RNA (siRNA). The human CD-147 siRNA and negative control siRNA were purchased from Genepharma (Shanghai, China). The siRNA sequence for CD-147 was: forward: 5'-GGU UCU UCG UGA GUU CCU CTT-3' and reverse: 5'-GAG GAA CUC ACG AAG AAC CTG-3'. The negative control siRNA sequence was: forward: 5'-UUC UCC GAA CGU GUC ACG UTT-3' and reverse: 5'-ACG UGA CAC GUU CGG AGA ATT-3' for NC. DharmaFect 4 transfection reagent was purchased from Dharmacon, Inc. (Lafayette, Co, USA). AGS cells were seeded in 6-well plates at a density of $2.5 \times 10^{5}$ cells/well in MEM and grown for $16 \mathrm{~h}$. Transfection was performed according to the instructions provided by Dharmacon using $4 \mu 1$ of DharmaFect-4 and a $100 \mathrm{nM} /$ well final siRNA concentration. The cells were cultured for another $24 \mathrm{~h}$. Total protein extracts were isolated and analyzed using anti-CD-147 (Invitrogen, Carlsbad, CA, USA) and GAPDH (Kangcheng, Shanghai, China) antibody immunoblotting. The cells were collected, washed twice with pre-cold PBS, and invasion was measured.

Western blot analysis. Cells were lysed in SDS lysis buffer on ice for $30 \mathrm{~min}$. Cell debris was removed by centrifugation at $14,000 \mathrm{x} \mathrm{g}$ at $4^{\circ} \mathrm{C}$ for $5 \mathrm{~min}$, and protein contents of the cell lysates were determined using a Bio-Rad protein assay kit (Hercules, CA, USA). Cell lysates with equal protein content were then loaded and separated by $12 \%$ SDS-PAGE. The protein bands were electrotransferred onto PVDF membrane and blocked with $5 \%$ non-fat milk in TBS/T buffer $(20 \mathrm{mmol} / \mathrm{l}$ Tris base, $135 \mathrm{mmol} / 1 \mathrm{NaCl}, 0.1 \%$ Tween-20, $\mathrm{pH}$ 7.6) for $1 \mathrm{~h}$. After incubation of the membrane with the appropriate antibodies, i.e., anti-phosphorylated or non-phosphorylated ERK, anti-CD-147, MMP-2 and MMP-9 (all from Cell Signaling Technology, MA, USA), for at least $4 \mathrm{~h}$, specific protein bands were visualized using SuperSignal West Pico/Fico chemiluminescent substrate (Millipore Co., Bedford, MA, USA). As an internal control, the GAPDH contents in the samples were also immunoblotted using polyclonal anti-actin antibody as the primary antibody.

Invasion assay. Invasion of gastric cancer cells was measured using the BD BioCoat ${ }^{\mathrm{TM}}$ BD Matrige ${ }^{\mathrm{TM}}$ invasion chamber (BD Biosciences, San Jose, USA) according to the manufacturer's instructions. Briefly, AGS and MKN-45 cells were treated with the inhibitor or siRNA for $24 \mathrm{~h}$. The cells were seeded in the membrane of the upper chamber of the Transwell at a concentration of $3-5 \times 10^{5} \mathrm{cells} / \mathrm{ml}$ in $2 \mathrm{ml}$ of DMEM medium. The medium in the upper chamber was serum-free. The medium in the lower chamber contained $5 \%$ fetal calf serum 

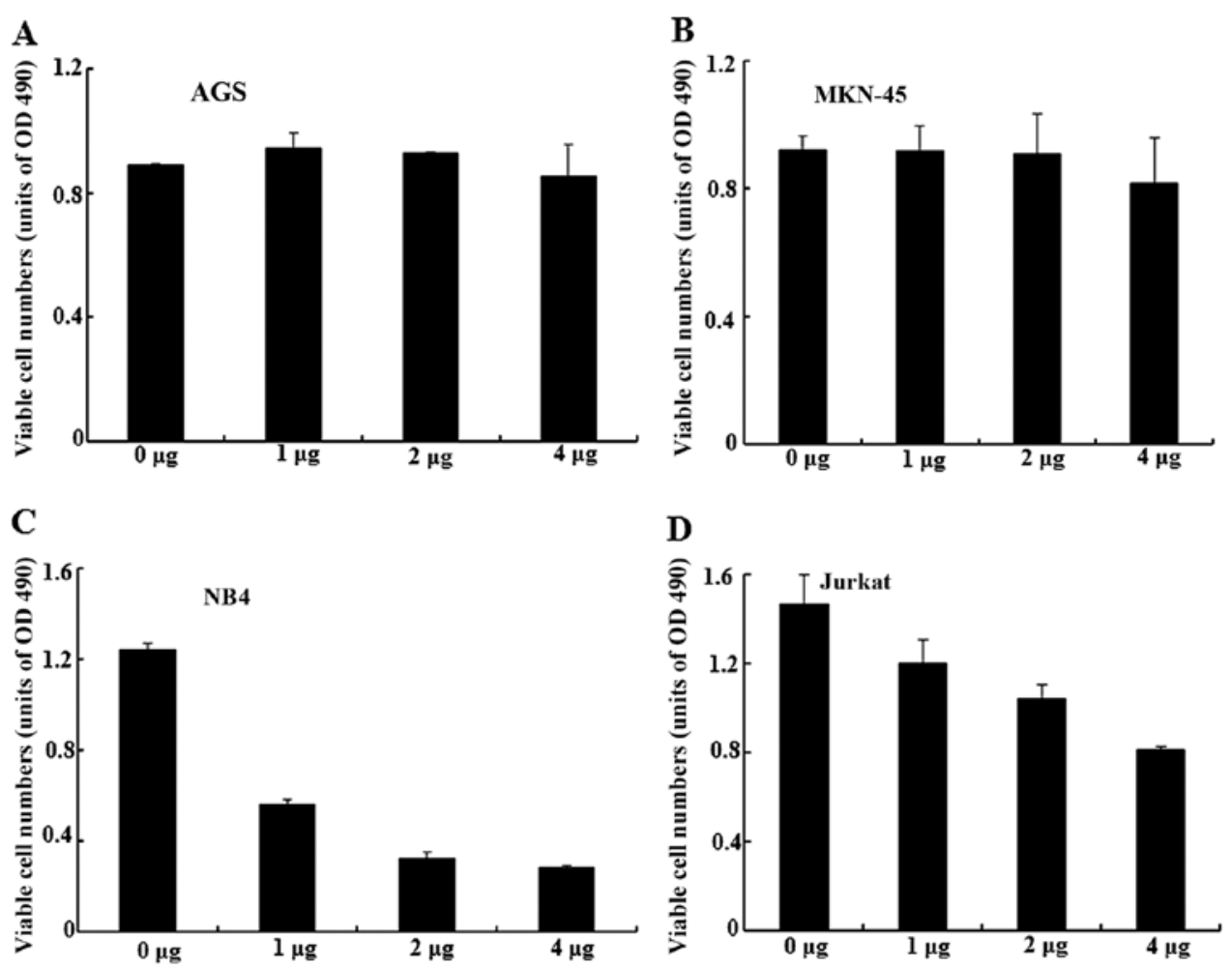

Figure 1. Ara-C did not inhibit the growth of AGS and MNK-45 gastric cancer cells. (A and B) AGS and MKN-45 cells were treated with Ara-C ( $0,1,2$ and $4 \mu \mathrm{g}$ ) for $24 \mathrm{~h}$. (C and D) NB4 and Jurkat cells were incubated with Ara-C $(0,1,2$ and $4 \mu \mathrm{g})$ for $24 \mathrm{~h}$. The anti-proliferative effect of Ara-C was detected by the CCK-8 kit.

as a source of chemoattractants. The cells that passed through the Matrigel-coated membrane were counted.

Statistical analysis. Each sample was analyzed in triplicate, and experiments were repeated three times. In all figures, error bars are standard deviations. Statistical analyses were performed using Microsoft Office Excel 2003 (Microsoft, Albuquerque, New Mexico, USA) and Statisca ver. 10 (StatSoft, Tulsa, OK, USA). Differences between mean values were evaluated by the unpaired t-test. Differences were considered statistically significant at $\mathrm{P}<0.05$.

\section{Results}

Ara-C did not induce the inhibition of proliferation in gastric cancer cells. AGS and MKN-45 gastric cancer cells were treated with Ara-C $(0,1,2,4 \mu \mathrm{g})$ for $24 \mathrm{~h}$ (Fig. 1). The results indicated that Ara-C did not inhibit the proliferation of gastric cancer cells (Fig. 1A and B). NB4 and Jurkat Ara-C-sensitive cells were treated with Ara-C $(0,1,2$ and $4 \mu \mathrm{g})$ for $24 \mathrm{~h}$. The data showed that Ara-C inhibited the proliferation of NB4 and Jurkat cells in a concentration gradient-dependent manner (Fig. 1C and D).

Ara-C induces potentialization of invasiveness and the activation of MMP-2 and -9 in gastric cancer cells. After the treatment of AGS and MKN-45 cells with Ara-C (0, 1, 2 and $4 \mu \mathrm{g}$ ) for $24 \mathrm{~h}$, the invasion of these gastric cancer cells was detected. The data showed that Ara-C $(0,1,2$ and $4 \mu \mathrm{g})$ did not suppress AGS and MKN-45 cell invasion, but increased invasion depending on the Ara-C dose (Fig. 2A and C). The activity of MMP-2 and -9 was analyzed by gelatinase zymography experiments. The results indicated that the activity of MMP-2 and -9 was enhanced by Ara- $C$ concentration in a gradient-dependent manner in the supernatant of AGS and MKN-45 cells (Fig. 2B and D).

Ara-C induces the expression of MMP-2 and -9, and CD147 in AGS and MKN-45 cells. Ara-C-induced MMP-2 and -9 activity allows us to determine whether CD-147 is involved in this process, as the literature supports that CD-147 is involved in the regulation of MMP-2 and -9 in tumor cell invasion (11-13). CD-147 expression was evaluated after AGS and MKN-45 cells were treated with Ara-C $(0,1,2$ and $4 \mu \mathrm{g})$ for $24 \mathrm{~h}$. The results showed that Ara-C significantly upregulated CD-147 mRNA and protein levels (Fig. 3A-D). The expression of MMP-2 and MMP-9 was also analyzed, and the results showed that Ara-C significantly upregulated MMP-2 and -9 mRNA and protein levels (Fig. 3A-D).

CD147 siRNAs inhibit Ara-C induced invasion and restore its anti-proliferation activity in gastric cancer cells. To determine whether Ara-C mediates the CD-147-MMP-2/MMP-9 signaling pathway involved in gastric cancer cell invasiveness, CD-147 siRNAs were transfected into AGS cells for $24 \mathrm{~h}$. The cells were treated with or without $4 \mu \mathrm{g}$ Ara-C, and western blotting revealed that Ara-C-inducing MMP-2/MMP-9 expression was inhibited by CD-147 siRNAs (Fig. 4A). Invasive in vitro experiments showed that CD-147 siRNAs completely blocked off the Ara-C increased gastric cancer cell invasiveness. At the same time, CD-147 siRNAs also restored the growth inhibitory effect of Ara-C in gastric cancer cells (Fig. 4B and C). 
A

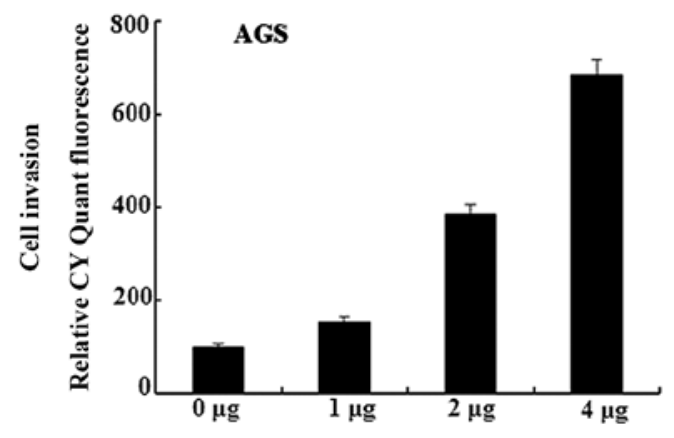

C

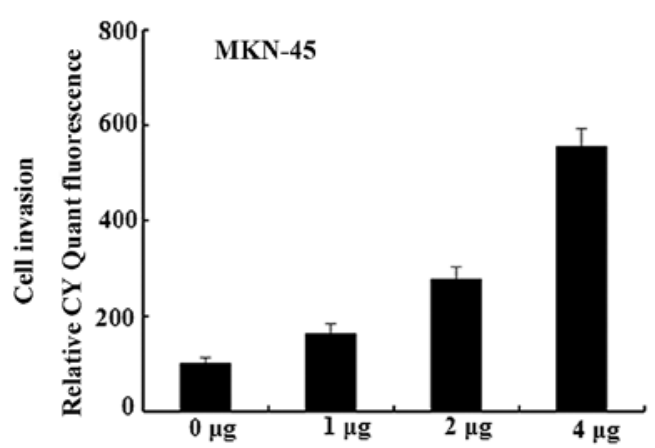

B

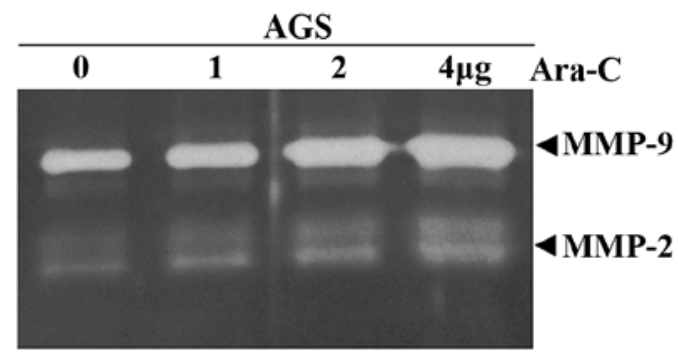

D

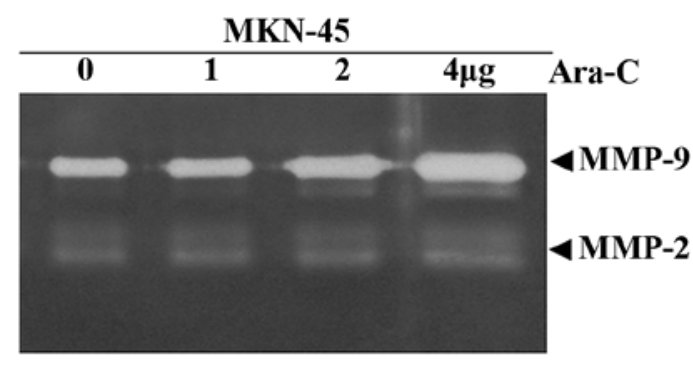

Figure 2. Ara-C induced the activation of MMP-2 and -9 and the increased invasiveness of AGS and MNK-45 cells. (A and C) AGS and MKN-45 cells were seeded in the membrane of the upper chamber of the Transwell at a concentration of 3-5x $10^{5} \mathrm{cells} / \mathrm{ml}$ in $2 \mathrm{ml}$ of DMEM medium with Ara-C ( $0,1,2$ and $4 \mu \mathrm{g}$ ). Cells that passed through the Matrigel-coated membrane were counted. Invasive changes in gastric cancer cells were analyzed by aggressive kit. (B and D) AGS and MKN-45 cells were treated with Ara-C $(0,1,2$ and $4 \mu \mathrm{g})$ for $24 \mathrm{~h}$. Presence of activity of matrix metalloproteinases in the cell supernatant was analysed by zymography on $10 \%$ polyacrylamide gels containing $2 \%$ gelatin and overnight incubation at $37^{\circ} \mathrm{C}$. The gels were stained with Coomassie brilliant blue R-250.

A

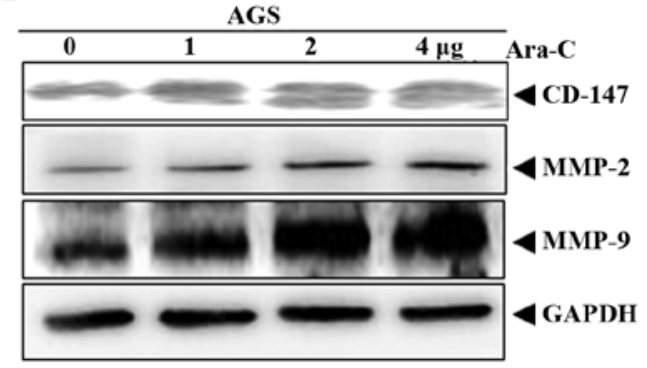

B

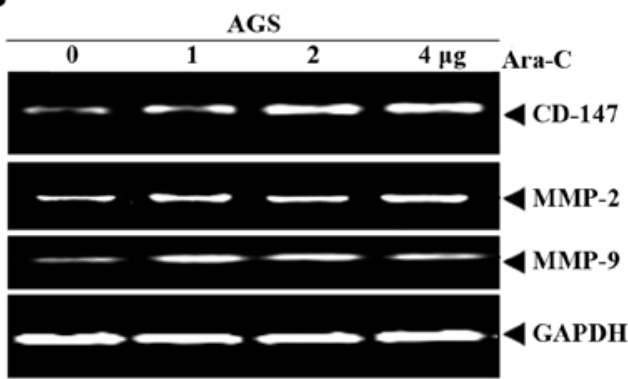

C

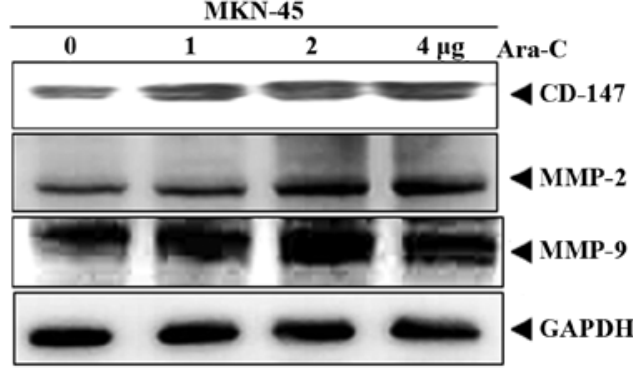

D

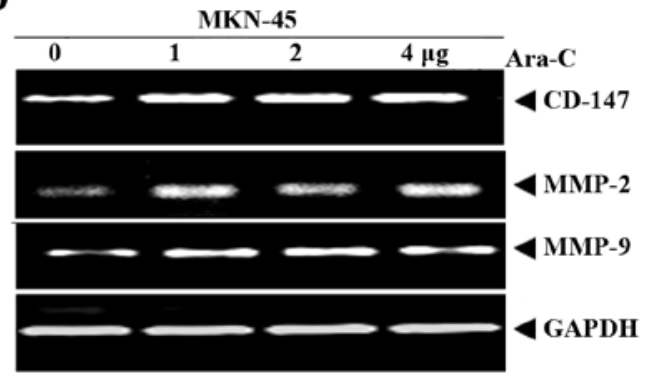

Figure 3. Ara-C induced the expression of MMP-2 and -9 , and CD-147 in AGS and MKN-45 cells. AGS and MKN- 45 cells were treated with Ara-C $(0,1,2$ and $4 \mu \mathrm{g}$ ) for $24 \mathrm{~h}$. (A and B) MMP-2 and -9, and CD-147 protein levels were detected by western blotting with GAPDH as the loading control. (C and D) MMP-2 and -9 , and CD-147 mRNA levels were analyzed by RT-PCR with GAPDH as the loading control.

Ara-C induces the expression of $M M P-2$ and -9 , and $C D-147$ via ERK activated in gastric cancer cells. The activation of
ERK signaling pathway is closely associated with activation of the CD-147-MMP-2/MMP-9 signaling pathway $(14,15)$. 
A

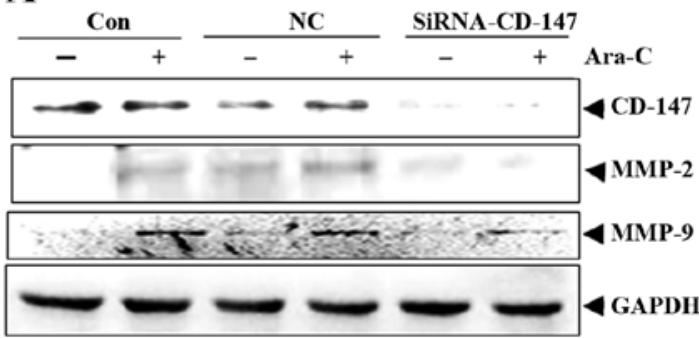

\section{B}

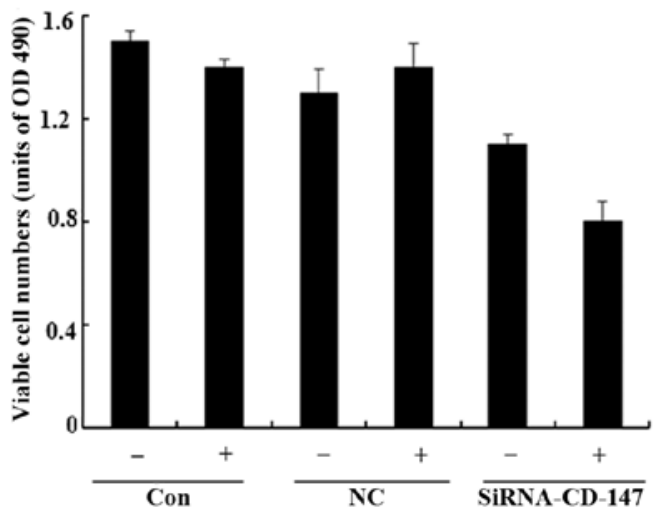

C

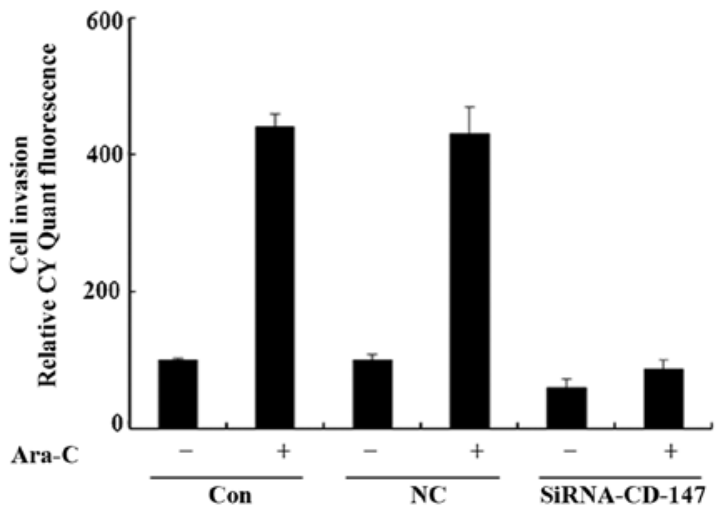

Figure 4. CD-147 siRNA blocked MMP-2 and MMP-9 expression induced by Ara-C, restored the inhibitory activity of Ara-C and blocked the invasion of Ara-C in AGS cells. SiRNAs specifically against CD-147 or negative control siRNA (NC) were transiently transfected into AGS cells. One day after transfection, the cells were incubated with or without $4 \mu \mathrm{g}$ Ara-C for $24 \mathrm{~h}$. (A) MMP-2 and -9, and CD-147 were detected by western blotting with GAPDH as the loading control. (B) Cell viability was evaluated by the CCK-8 kit. (C) Invasiveness of AGS cells was determined. Invasive cells were observed under an inverted microscope, and the number of invasive cells was counted.

A

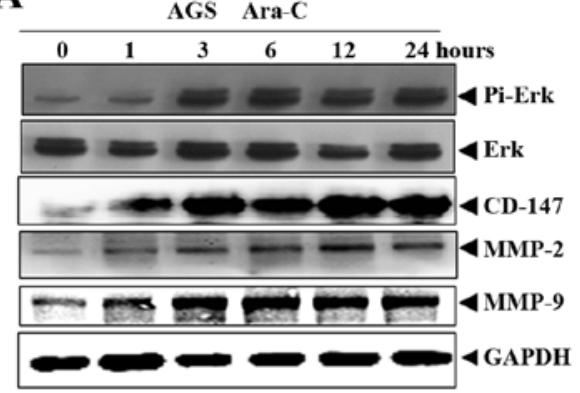

C

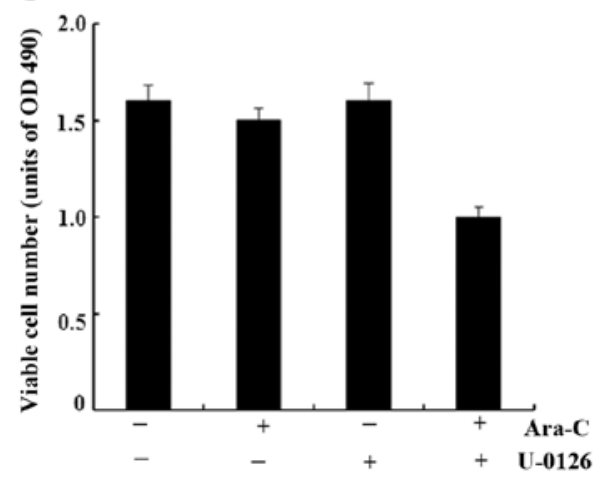

B

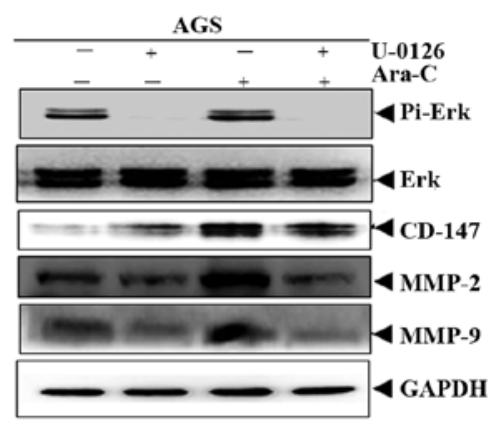

D

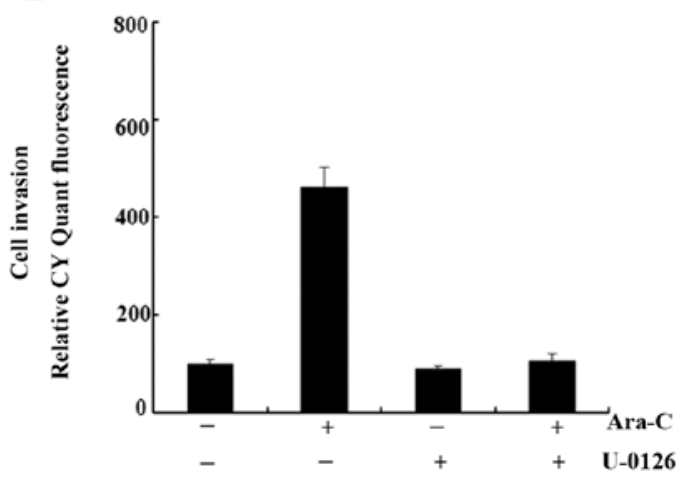

Figure 5. ERK inhibitors (U-0126) restored the inhibitory activity of Ara-C and blocked the invasion of AGS cells induced by Ara-C. (A) AGS cells were treated with $4 \mu \mathrm{g}$ Ara-C for the indicated time-points. Pi-ERK, ERK, MMP-2, MMP-9 and CD-147 levels were analyzed by western blotting with GAPDH as the loading control. (B) Pre-incubation of AGS cells with $10 \mu \mathrm{M} \mathrm{U}-0126$ for $2 \mathrm{~h}$, followed by incubation with or without $4 \mu \mathrm{g}$ Ara-C for $24 \mathrm{~h}$. Western blotting detected Pi-ERK, ERK, CD-147, MMP-2 and MMP-9 with GAPDH as the loading control. (C) Pre-incubation of AGS cells with $10 \mu \mathrm{M}$ U0126 for $2 \mathrm{~h}$, followed by incubation with or without $4 \mu \mathrm{g}$ Ara-C for $24 \mathrm{~h}$. CCK-8 kit detected cell proliferation. (D) U-0126 was used to pre-treat AGS cells for $2 \mathrm{~h}$. Subsequently, gastric cancer cells were incubated with or without $4 \mu \mathrm{g}$ Ara-C for $24 \mathrm{~h}$. Invasiveness of AGS cells was determined. Invasive cells were observed under an inverted microscope. 
In order to determine the role of ERK signaling molecules in Ara-C-induced CD-147 and its downstream MMP-2 and -9, AGS cells were treated with $4 \mu \mathrm{g}$ Ara-C at the indicated time points. MMP-2 and -9, and CD-147 protein levels were upregulated after activation of ERK signaling molecules (Fig. 5A). U-0126, the ERK signaling molecule inhibitor (16-18), was used to pre-treat gastric cancer cells was found to block Ara-C-induced ERK-CD-147 -MMP-2/MMP-9 activation (Fig. 5B). Accordingly, U-0126 allowed Ara-C to inhibit gastric cancer cell proliferation activity (Fig. 5C). In invasive in vitro experiments it was observed that $4 \mu \mathrm{g}$ Ara-C increased the invasiveness of gastric cancer cells, while the ERK inhibitor U-0126 reduced gastric cancer cell invasion. More importantly, $\mathrm{U}-0126$ completely blocked off the Ara-C increased gastric cancer cell invasiveness (Fig. 5D).

\section{Discussion}

In this study, we used Ara-C treated gastric cancer cells to determine whether Ara-C inhibited cell proliferation and induced apoptosis in gastric cancer cells. The results show that Ara-C did not inhibit gastric cancer cells. By contrast, Ara-C promoted gastric cancer cell invasiveness. Furthermore, we revealed that the activation of ERK involved in Ara-C upregulated CD-147-MMP-2/MMP-9 expression which could enhance the invasive properties of gastric cancer cells.

CD-147 is a highly glycosylated transmembrane protein belonging to the immunoglobulin superfamily, which can induce the production of its downstream MMP-2 and -9 when activated by certain molecules. These molecules are involved in cell migration and invasiveness (19-21). Notably, Ara-C can increase the expression of CD-147 in gastric cancer cells. We also observed that Ara-C activated MMP-2 and MMP-9 expressions. SiRNA-CD-147 resisted Ara-C-induced invasiveness increase in gastric cancer cells. Following this, Ara-C-induced MMP-2 and -9 was restored by siRNA-CD-147. These findings suggest that Ara-C enhanced gastric cancer cell invasiveness by CD-147-MMP-2/MMP-9 signaling molecules.

As the abnormal activation of ERK signaling pathway may trigger tumor cell CD-147 signaling pathway $(22,23)$, whether Ara-C can induce CD-147 signaling molecules by ERK in gastric cancer cells remains to be elucidated. Treatment of gastric cancer cells using Ara-C at different concentrations for $24 \mathrm{~h}$ showed that MMP-2 and -9, and CD-147 were upregulated in an Ara-Cdependent manner when the activation of ERK was observed. It was hypothesized that Ara-C upregulated CD-147-MMP-2/ MMP-9 expression through the ERK activation of Ara-C. This observation was confirmed by U-0126, the ERK inhibitor, which blocked the ERK activation of Ara-C, following restoration of MMP-2 and -9, and CD-147 upregulation in Ara-C-treated gastric cancer cells. U-0126 inhibited gastric cancer cell invasion of Ara-C induction, indicating that the Ara-C induction increased gastric cancer cell invasion by activation of ERK. The manner in which Ara-C activated ERK, as well as the activation of CD-147-MMP-2/MMP-9 require further investigation.

In summary, the results suggest that Ara-C did not inhibit gastric cancer cell proliferation and viability. By contrast, Ara-C activated the ERK signaling pathway in gastric cancer cells, which is involved in gastric cancer cell proliferation resistance and activated the invasiveness of gastric cancer cells via
CD-147-MMP-2/MMP-9 signaling molecules. These results show that Ara-C alone may not be used for the treatment of patients with gastric cancer, and application of Ara-C treatment for gastric cancer patients points may involve potential risks.

\section{Acknowledgements}

This study was supported in part by grants from National Natural Science Foundation of China (81172322, 81101642), Science and Technology Commission of Shanghai Municipality (11ZR1421000), Science and Technology Fund of Shanghai Jiao Tong University School of Medicine (YZ1027).

\section{References}

1. Li R, Chen WC, Pang XQ, et al: Combined effect of sCD40L and PI3K siRNA on transplanted tumours growth and microenvironment in nude mice with gastric cancer. Mol Biol Rep 39: 8755-8761, 2012.

2. Pietrantonio F, De Braud F, Da Prat V, et al: A review on biomarkers for prediction of treatment outcome in gastric cancer. Anticancer Res 33: 1257-1266, 2013.

3. Braun S, Kentenich C, Janni W, et al: Lack of effect of adjuvant chemotherapy on the elimination of single dormant tumor cells in bone marrow of high-risk breast cancer patients. J Clin Oncol 18: 80-86, 2000

4. Aogi K, Rai Y, Ito Y, et al: Efficacy and safety of ixabepilone in taxane-resistant patients with metastatic breast cancer previously treated with anthracyclines: results of a phase II study in Japan. Cancer Chemother Pharmacol 71: 1427-1433, 2013.

5. Harland S, Staffurth J, Molina A, et al: Effect of abiraterone acetate treatment on the quality of life of patients with metastatic castration-resistant prostate cancer after failure of docetaxel chemotherapy. Eur J Cancer 49: 3648-3657, 2013.

6. Sawai K, Goi T, Koneri K, et al: Partial response after transcatheter arterial infusion chemotherapy in a patient with systemic chemotherapy-resistant unresectable colon cancer and hepatic metastasis: (case report). World J Surg Oncol 11: 203, 2013.

7. Oyamada Y, Maeshima A, Takeuchi K and Kato R: A case of lung cancer resistant to pemetrexed responding to S-1 monotherapy. Gan To Kagaku Ryoho 40: 781-784, 2013 (In Japanese).

8. Neuzillet C, Hentic O, Rousseau B, et al: FOLFIRI regimen in metastatic pancreatic adenocarcinoma resistant to gemcitabine and platinum-salts. World J Gastroenterol 18: 4533-4541, 2012.

9. Galmarini CM, Mackey JR and Dumontet C: Nucleoside analogues and nucleobases in cancer treatment. Lancet Oncol 3: 415-424, 2002.

10. Löwenberg B: Sense and nonsense of high-dose cytarabine for acute myeloid leukemia. Blood 121: 26-28, 2013.

11. Fan X, Wu W, Shi $\mathrm{H}$ and Han J: RNA interference targeting CD147 inhibits the invasion of human cervical squamous carcinoma cells by downregulating MMP-9. Cell Biol Int 37: 737-741, 2013.

12. Zhao S, Ma W, Zhang M, et al: High expression of CD147 and MMP-9 is correlated with poor prognosis of triple-negative breast cancer (TNBC) patients. Med Oncol 30: 335, 2013.

13. Piao S, Zhao S, Guo F, et al: Increased expression of CD147 and MMP-9 is correlated with poor prognosis of salivary duct carcinoma. J Cancer Res Clin Oncol 138: 627-635, 2012.

14. Kim JY, Kim WJ, Kim H, et al: The stimulation of CD147 induces MMP-9 expression through ERK and NF-kappaB in macrophages: implication for atherosclerosis. Immune Netw 9: 90-97, 2009.

15. Farabegoli F, Papi A and Orlandi M: (-)-Epigallocatechin-3gallate down-regulates EGFR, MMP-2, MMP-9 and EMMPRIN and inhibits the invasion of MCF-7 tamoxifen-resistant cells. Biosci Rep 31: 99-108, 2011.

16. Chow S, Patel H and Hedley DW: Measurement of MAP kinase activation by flow cytometry using phospho-specific antibodies to MEK and ERK: potential for pharmacodynamic monitoring of signal transduction inhibitors. Cytometry 46: 72-78, 2001.

17. Fukazawa H, Noguchi K, Murakami Y and Uehara Y: Mitogenactivated protein/extracellular signal-regulated kinase kinase (MEK) inhibitors restore anoikis sensitivity in human breast cancer cell lines with a constitutively activated extracellular-regulated kinase (ERK) pathway. Mol Cancer Ther 1: 303-309, 2002. 
18. Sunayama J, Matsuda K, Sato A, et al: Crosstalk between the $\mathrm{PI} 3 \mathrm{~K} / \mathrm{mTOR}$ and MEK/ERK pathways involved in the maintenance of self-renewal and tumorigenicity of glioblastoma stem-like cells. Stem Cells 28: 1930-1939, 2010.

19. Hao JL, Cozzi PJ, Khatri A, et al: CD147/EMMPRIN and CD44 are potential therapeutic targets for metastatic prostate cancer. Curr Cancer Drug Targets 10: 287-306, 2010.

20. Kanekura T and Chen X: CD147/basigin promotes progression of malignant melanoma and other cancers. J Dermatol Sci 57: 149-154, 2010.

21. Nabeshima K, Iwasaki H, Koga K, et al: Emmprin (basigin/ CD147): matrix metalloproteinase modulator and multifunctional cell recognition molecule that plays a critical role in cancer progression. Pathol Int 56: 359-367, 2006.
22. Boulos S, Meloni BP, Arthur PG, et al: Evidence that intracellular cyclophilin A and cyclophilin A/CD147 receptor-mediated ERK1/2 signalling can protect neurons against in vitro oxidative and ischemic injury. Neurobiol Dis 25: 54-64, 2007.

23. Kim K, Kim H, Jeong K, et al: Release of overexpressed CypB activates ERK signaling through CD147 binding for hepatoma cell resistance to oxidative stress. Apoptosis 17: 784-796, 2012. 